DOI: 10.17805/trudy.2016.6.3

\title{
ПСИХОЛОГИЧЕСКИЕ УСЛОВИЯ ФОРМИРОВАНИЯ ПРОФЕССИОНАЛЬНЫХ ЗНАНИЙ, НАВЫКОВ, УМЕНИЙ
}

\author{
Н. И. Федотова \\ (Московский гуманитарный университет)
}

Аннотация: В статье говорится об основных психологических условиях формирования профессиональных знаний, навыков и умений у обучающихся высшей школь.

Ключевые слова: знания; умения; навыки; психологические условия формирования; обучение в вузе

\section{PSYCHOLOGICAL PRECONDITIONS OF BUILDING PROFESSIONAL KNOWLEDGE, SKILLS, AND ABILITIES}

\author{
N. I. Fedotova \\ (Moscow University for the Humanities)
}

Abstract: The article examines the main psychological conditions of developing professional knowledge, skills and abilities in higher school students.

Keywords: knowledge; abilities; skills; psychological conditions of development; studying in a higher education institution

Для формирования профессиональных знаний, навыков, умений необходимо воздействовать не только на познавательные процессы, но и на направленность, чувства, волю, интересы, психические состояния студентов. Рассмотрим важнейшие психологические условия формирования профессиональных знаний, навыков, умений у обучающихся, учитывая единство их внешней практической и внутренней психической деятельности.

Решающее значение имеет организация учебной деятельности обучающихся. Согласно теории А. Н. Леонтьева, П. Я. Гальперина, знания, подлежащие усвоению, как пишет Н. Ф. Талызина, не могут быть переданы в готовом виде, путем простого сообщения или показа. Они могут быть усвоены только в результате определенной деятельности учащихся, т. е. в результате выполнения определенной системы действий (Талызина, 1998: 112).

Определим сначала отдельно условия формирования знаний, навыков, умений, а затем условия превращения их в целостную систему. 
Преподавателю следует исходить из того, что обучающийся лучше овладевает знаниями на основе активности познавательных процессов, если его действия побуждаются прежде всего положительными мотивами. Овладение знаниями требует четкого и точного их восприятия, осмысливания, запоминания, применения на практике.

Усвоение знаний, предусмотренных программами, является существенной стороной обучения в вузе. Усвоение - сложная познавательная деятельность обучающихся, основу которой составляют умственные действия. Усвоение знаний по предмету представляет собой овладение системой его понятий, которое складывается из понимания содержания понятий, выделения существенного, главного в тех или иных предметах, явлениях; четкого уяснения объема понятий, представления о том круге явлений, на которые распространяется данное понятие; умения устанавливать связи одного понятия с другими, в том числе и с понятиями из смежных дисциплин; умения использования их для решения практических задач.

Ясное понимание значения знаний, самостоятельность в их приобретении и проверке, творческое применение к решению различных задач обеспечивает их глубокое и прочное усвоение. Овладению специальной терминологией помогает применение инновационных и традиционных форм демонстрации учебного материала.

Немаловажное значение имеет также показ вновь поступившим обучающимся лабораторий вуза, различных кабинетов. Полученные впечатления вызывают у них, как правило, интерес к учению, укрепляют стремление к овладению профессией. При этом не следует акцентировать внимание обучающихся на сложности их будущей профессии. Глубокому и творческому усвоению знаний способствует создание на занятиях проблемных ситуаций, при которых знания усваиваются не как готовые, данные преподавателем, а через процесс решения задачи, поиска или выбора ответа на вопрос, нахождение вывода и т. д.

Процесс субъективного открытия неизвестного в проблемной ситуации осуществляется как поисковая познавательная деятельность субъекта, завершающаяся усвоением нового и порождением психических новообразований.

Проблемное обучение может иметь разные качественные уровни в зависимости от курса, степени владения предметом и т. д. Для усвоения знаний необходимо применять их на практике. Главная форма такого применения - решение задач. Именно в процессе активного практического использования знаний они становятся более обобщенными и твердыми, часть из них переходит в навыки и умения. Но тут выступает психологическое условие: учебная деятельность, не доставляющая внутреннего удовлетворения, не вызывающая активного мышления, внимания, па- 
мяти, воображения, не требующая творчества, инициативы, слабо влияет на полноту и глубину усвоения знаний. Поэтому важно, чтобы занятия проводились интересно, влияли на эмоции, чувства и мотивы поведения обучающихся (Гальперин, 1999).

Наиболее эффективноформируются навыки на основе глубокого осмысливания обучающимися того, что они должны делать, интереса к овладению действиями, знания своих ошибок, а также своевременного одобрения и поощрения успехов. Преподавателю все это надо учитывать, используя в обучении объяснение, оценку, лабораторные и практические работы, тренировки, оказывать помощь обучающимся в самостоятельной работе.

Совершенствование навыков зависит от их сложности, индивидуальных особенностей и психического состояния обучающегося, методики обучения и приближения его к условиям выполнения профессиональных обязанностей.

Навык складывается неравномерно, для него характерна остановка, задержка - плато. Это связано с утомлением, потерей интереса, ухудшением методических приемов, изменением обстановки, новыми трудностями. помогает более экономно и продуктивно улучшать навыки.

На формирование навыков влияют изменение работоспособности в течение недели (в какой день проводится упражнение), время суток. Поэтому овладение новыми и сложными навыками лучше начинать в первую половину средних дней недели, а повторение - в другое время.

Между навыками происходит взаимодействие (положительное и отрицательное). Поэтому переучивание сопряжено с особыми трудностями. Положительному переносу навыков способствуют сходные психические процессы, установки и общие приемы в работе (прежней и новой). Навыки могут ослабляться, утрачиваться. Это происходит вследствие их неиспользования в практике, отсутствия систематичности и длительных перерывов в повторениях, болезни, переутомления, сильного стресса. Быстрее утрачиваются сложные, недостаточно закрепленные навыки. Это необходимо учитывать, решая вопрос о готовности навыков. Научные данные и практика показывают, что механическая выработка навыков идет в несколько раз медленнее, чем сознательная (на основе понимания сути действий, причин допускаемых ошибок и т. д.).

Экспериментальные исследования П. Я. Гальперина показали значение ориентировки в действии, уяснения всех его реально существующих признаков. Это создает условия, при которых действие сразу (или через несколько упражнений) может быть выполнено правильно, без ошибок. Формирование умений предполагает повышение самоконтроля, управляемости действий в соответствии с лучшими образцами. Сравнение обучающимися своих реальных действий с показываемыми преподава- 
телями приемами, установление совпадения и различия между ними, внесение поправок в процесс деятельности и его настойчивое совершенствование - необходимая предпосылка укрепления умения. Накапливая профессиональные знания и вырабатывая навыки, преподавателю следует вооружать обучающихся рациональными способами их использования в различной обстановке на основе творческого осмысливания задач будущей деятельности.

Рассмотрим более общие условия формирования знаний, навыков, умений, превращения их совокупности в слаженную систему, обеспечивающую успех профессиональной деятельности. Одно из условий такого превращения - положительные мотивы учения студентов, их сознательность, дисциплинированность, организованность.

Развитие профессиональных знаний, навыков, умений обучающихся идет тем скорее, чем глубже и разностороннее разъясняются им требования будущей профессии, отрицательные последствия слабой подготовленности, показываются достижения выпускников. Практика вузовского обучения свидетельствует, что формирование системы профессиональных знаний, навыков, умений замедляется, если обучающийся слабо разобрался в задачах профессии, не проявляет интереса к своей специальности.

Лучшие преподаватели обращают особое внимание на то, чтобы правильно спланировать занятия, обеспечить успех учебы обучающихся, создать в студенческом коллективе хорошую психологическую атмосферу, своевременно предотвратить появление настроений, мешающих нормальной учебе. Если обучающийся правильно оценил значение своей будущей профессии, убедился в целесообразности и необходимости учения, если у него нет внутренних разногласий с тем, что он делает, то у него быстрее развивается единство знаний, навыков, умений.

Таким образом, повышение уровня мотивации и сознательного отношения обучающихся к учению - важное условие успешного формирования системы профессиональных знаний, навыков, умений.

Небывалый рост науки и техники, дальнейшее усложнение трудовой деятельности, всех профессий усилили зависимость формирования профессиональных знаний, навыков, умений у обучающихся от совершенствования и профессионализации их познавательных процессов: мышления, речи, воображения, внимания, памяти и т. д. Умелая профессиональная деятельность, творчество в труде невозможны, если познавательные процессы имеют серьезные недостатки: инертны, малоподвижны, неустойчивы, неточно отражают то, что нужно для успешных действий, медленно перерабатывают необходимую информацию.

Причиной неправильных профессиональных действий может стать неточность восприятия у бакалавра или магистра, невнимательность, 
инертность его мышления, эмоциональная напряженность, страх, неуверенность, слабость воли и навыков. Поэтому слаженность профессиональных знаний, навыков, умений у обучающихся формируется вместе с совершенствованием восприятия, внимания, представлений, памяти, воображения и других психических процессов. Заботясь об их совершенствовании у обучающихся, можно повлиять на повышение профессиональной подготовленности. Так, профессионально развитые воображение и мышление дают возможность в уме моделировать предстоящие действия, решать задачи, связанные с предвосхищением последствий практической деятельности.

Профессиональные знания, навыки, умения действенны не только благодаря специальному развитию психических познавательных процессов, но и физическим качествам обучающегося. Экспериментально доказано, что целенаправленные физические упражнения развивают не только физические, но и психологические качества, необходимую для каждого специалиста эмоционально-волевую устойчивость.

Большая роль в формировании профессиональных знаний, навыков, умений принадлежит целенаправленному применению различного рода технических средств обучения (ТСО). Именно с их помощью можно развивать и упрочивать знания, навыки, умения, придавать им гибкость.

TCO направлены на расширение возможностей преподавателя в учебном процессе. При использовании их происходит эмоциональнопсихологическое воздействие на студентов. Появляется возможность управления ходом поступления информации самими обучающимися, что существенным образом улучшает усвоение материала относительно независимо от текущего состояния и различия индивидуальных способностей и психологических особенностей каждого студента.

Особо важным средством профессиональной подготовки являются практика, стажировка, выполнение будущих обязанностей в реальных условиях профессиональной деятельности.

Анализируя процесс обучения, С. Л. Рубинштейн справедливо отмечал: «Как бы ни было велико значение специально выделенной учебной деятельности для овладения специальными знаниями и умениями как «техническими» компонентами той или иной жизненной профессиональной деятельности, подлинного мастерства, завершающего обучения какой-либо деятельности, человек достигает, не просто лишь обучаясь, а на основе предшествующего обучения, выполняя эту деятельность» (Рубинштейн, 2000: 243).

В преподавании каждого предмета учитывается тот уровень усвоения, на котором находится обучающийся. Таких уровней несколько.

Первый уровень усвоения сводится к распознаванию, различению, 
узнаванию или опознаванию объекта, изучения его в ряду других объектов.

Второй уровень характерен действиями по воспроизведению информации об объекте изучения, его свойствах, особенностях, характеристиках на уровне памяти или уровне понимания.

Третий уровень можно характеризовать степенью овладения умениями применять усвоенную информацию в практической сфере для решения некоторого класса задач.

Четвертый уровень усвоения, деятельность которого характеризует применение информации с широким переносом, может быть обеспечен на основе использования теории проблемного обучения. По данной теории проблемы (задачи) выступают как объект мышления. Это означает, что обучаемому даются такие задачи, которые он может решить только путем самостоятельного открытия. Для правильного решения таких задач обучающегося необходимо вооружить некоторым алгоритмом поиска (проб). В алгоритме поиска должны быть предусмотрены все возможные операции и их последовательность. Осуществив эти операции, обучаемый обязательно откроет, какая их последовательность ведет к цели, т. е. откроет алгоритм решения. (Дьяченко, Кандыбович, 1981).

В формировании профессиональных знаний, навыков, умений необходим индивидуальный подход, учет требований к особенностям личности обучающегося и «типа» его будущей профессии. Индивидуальные качества, существенно влияют на учебную деятельность обучающегося, выливаясь в индивидуальную динамику формирования знаний, навыков, умений.

Анализ проявлений индивидуальных свойств в профессиональной деятельности показывает, что эти проявления могут носить как целесообразный, так й нежелательный характер. Причем даже на базе ценных с точки зрения данной профессии свойств могут формироваться как положительные, так и отрицательные приемы деятельности. Поэтому управлять процессом формирования профессиональных знаний, навыков, умений необходимо как с учетом общего уровня усвоения, развития, возраста (учебная группа, курс), так и индивидуального уровня и индивидуальных особенностей обучающегося.

\section{СПИСОК ЛИТЕРАТУРЫ}

Гальперин, П. Я. (1999) Введение в психологию : учебное пособие для вузов. М. : Книжный дом «Университет». 332 с.

Дьяченко, М. И., Кандыбович Л. А. (1981) Психология высшей школы. Минск : Изд-во БГУ им. В. И. Ленина. 383 с.

Рубинштейн, С. Л. (2000) Основы общей психологии. СПб. : Издательство «Питер». 712 с. 
Талызина, Н. Ф. (1998) Педагогическая психология : учеб. пособие для студ. сред. пед. учеб. заведений. М. : Издательский центр «Академия». 288 с. Дата поступления: 11.12.2016 г.

Федотова Наталья Игоревна - кандидат психологических наук, доцент кафедры педагогики и психологии высшей школы Московского гуманитарного университета. Адрес: 111395, Россия, г. Москва, ул. Юности, д. 5 Тел.: +7 (499) 374-74-59. Эл. адрес: fedotova1973@mail.ru

Fedotova Natal'ia Igorevna, Candidate of Psychology, Associate Professor, Department of the Pedagogy and Psychology of Higher School, Moscow University for the Humanities. Postal address: 5 Yunosti St., 111395 Moscow, Russian Federation. Tel.:+7 (499) 374-74-59. E-mail: fedotova1973@mail.ru

\section{Для цитирования:}

Федотова Н. И. Психологические условия формирования профессиональных знаний, навыков, умений [Электронный ресурс] // Научные труды Московского гуманитарного университета. 2016, № 6. URL: http://journals.mosgu.ru/trudy/article/view/375 (дата обращения: дд.мм.гг.). 